\title{
Erratum to: Identification of invasion proteins of Cryptosporidium parvum
}

Preeti Singh $^{1}$ - Bijay Ranjan Mirdha ${ }^{1}$ - Alagiri Srinivasan ${ }^{1}$ •

Lokesh A. Rukmangadachar ${ }^{1} \cdot$ Sundeep Singh $^{1} \cdot$ Pratibha Sharma $^{1}$.

Gururao Hariprasad $^{1} \cdot$ Kalpana Luthra $^{1}$

Published online: 2 April 2016

(C) Springer Science+Business Media Dordrecht 2016

Erratum to: World J Microbiol Biotechnol (2015)

\section{1:1923-1934}

DOI 10.1007/s11274-015-1936-9

The co-author Dr. Gururao Hariprasad from the All India Institute of Medical Sciences in New Delhi wishes to correct his name. The correct name order is GURURAO HARIPRASAD (and not HARIPRASAD GURURAO as stated in the article).

The online version of the original article can be found under doi:10.1007/s11274-015-1936-9.

Alagiri Srinivasan

srinismbl@ rediffmail.com

Preeti Singh

preetivs.aiims@gmail.com

1 AIIMS, New Delhi, Delhi, India 